LEMOS, Tayara Talita; DE ALMEIDA JUNIOR, Benedito Silva e DE MELLO, Larissa Fernandes Ranieri. O povo contra a democracia: o problema da abstenção dos indivíduos em relação ao exercício de seus direitos políticos. Revista Eletrônica Direito e Política, Programa de PósGraduação Stricto Sensu em Ciência Jurídica da UNIVALI, Itajaí, v.10, n.4, 30 quadrimestre de 2015. Disponível em: www.univali.br/direitoepolitica - ISSN 1980-7791.

\title{
O POVO CONTRA A DEMOCRACIA: O PROBLEMA DA ABSTENÇÃO DOS INDIVÍDUOS EM RELAÇÃO AO EXERCÍCIO DE SEUS DIREITOS POLÍTICOS
}

\author{
THE PEOPLE AGAINST DEMOCRACY: THE PROBLEM OF INDIVIDUALS \\ ABSTENTION CONCERNING TO THE EXERCISE OF THEIR \\ POLITICAL RIGHTS
}

Tayara Talita Lemos ${ }^{1}$

Benedito Silva de Almeida Junior ${ }^{2}$

Larissa Fernandes Ranieri de Mello $^{3}$

SUMÁRIO: Introdução; 1 . Tocqueville e os limites da liberdade no âmbito da "nova" democracia - o problema da insuficiência do sistema representativo; 2. Hannah Arendt: A importância do espaço público e da participação política na legitimação e na construção das ações; 3. Habermas e a relação das autonomias pública e privada: o problema da legitimidade das decisões políticas; 4 . Kant e a "Menoridade Política"; Considerações Finais; Referências das Fontes Citadas.

\section{RESUMO}

Esta pesquisa objetiva perquirir as causas pelas quais os indivíduos, por vezes, se abstém de exercer seus direitos políticos, alienando seu poder de decisão para um grupo seleto de pessoas. A hipótese que perpassa todo o trabalho é que o modelo liberal de democracia exacerba a importância das liberdades individuais, fazendo com que os indivíduos tendam a nutrir certa indiferença ou a se interessar menos para os/pelos assuntos de interesse público. O sistema representativo de governo também é visto como grande responsável por esse fenômeno, na medida em que quase sempre restringe o processo de participação

\footnotetext{
${ }^{1}$ Bacharel em Direito pela Faculdade de Direito de Franca (2006), especialista em Direito Público (pós graduação lato sensu em Direito Público - Universidade de Franca-2007), Mestre pela Universidade Federal de Minas Gerais - UFMG, foi bolsista CAPES/REUNI, Doutoranda em Direito pela Universidade Federal de Minas Gerais - UFMG. É professora assistente na Universidade Federal de Juiz de Fora, campus Governador Valadares. Email: tayara.lemos@ufjf.edu.br

2 Graduando em Direito na Universidade Federal de Juiz Fora - Campus Governador Valadares, Minas Gerais, Brasil. Email: benejunior182@hotmail.com

${ }^{3}$ Graduanda em Direito pela Universidade Federal de Juiz Fora - Campus Governador Valadares, Minas Gerais, Brasil. Email: larissaranieri@live.com
} 
LEMOS, Tayara Talita; DE ALMEIDA JUNIOR, Benedito Silva e DE MELLO, Larissa Fernandes Ranieri. O povo contra a democracia: o problema da abstenção dos indivíduos em relação ao exercício de seus direitos políticos. Revista Eletrônica Direito e Política, Programa de PósGraduação Stricto Sensu em Ciência Jurídica da UNIVALI, Itajaí, v.10, n.4, 30 quadrimestre de 2015. Disponível em: www.univali.br/direitoepolitica - ISSN 1980-7791.

política dos cidadãos à mera escolha de representantes. A partir daí, poder-se-á aferir os reflexos desse fenômeno na questão da legitimidade das decisões políticas, pois na medida em que todo o sistema político tem como pressuposto lógico-fundamental a soberania popular, a falta da deliberação pública dos indivíduos compromete todo esse sistema.

PALAVRAS-CHAVE: Democracia; Liberdade; Direitos políticos; Espaço público; Esfera pública.

\section{ABSTRACT}

This research aims to look for the reasons why individuals occasionally avoid exercising their political rights, transferring their power of decision to a select group of people. The hypothesis that crosses all this article is that the liberal model of democracy exacerbates the importance of individual freedoms, so that individuals tend to feed certain indifference or to be less interested for/by matters of public interest. The representative system of government is also seen as big responsible for this phenomenon, once it often restricts the process of citizens' political participation to the merely choice of representatives. From there, it will be possible to measure the reflexes of this phenomenon on the legitimacy of political decisions, since sovereignty of the people is the logical and fundamental assumption of the entire political system, the lack of public deliberation of individuals committs all of it.

KEYWORDS: Democracy; Liberty; Political rights; public space; public sphere.

\section{INTRODUÇÃO}

A crescente necessidade de construção de mecanismos que possibilitem a participação política dos indivíduos nos processos políticos já é velha conhecida da Ciência Política e da Teoria do Direito. A democracia liberal e seu sistema representativo de governo já não conseguem mais dar conta da complexidade e da contingencialidade da sociedade contemporânea, estando já, de certa forma, esgotados.

São vários os fatores que apontam para essa "sobrecarga" do sistema representativo de governo - sobrecarga aqui no sentido do abismo que claramente se observa entre as expectativas geradas e os resultados obtidos. 0 crescente número de votos brancos e nulos (sem se falar das abstenções, que seguem essa tendência), o aumento do pessimismo em relação ao futuro, bem 
LEMOS, Tayara Talita; DE ALMEIDA JUNIOR, Benedito Silva e DE MELLO, Larissa Fernandes Ranieri. O povo contra a democracia: o problema da abstenção dos indivíduos em relação ao exercício de seus direitos políticos. Revista Eletrônica Direito e Política, Programa de PósGraduação Stricto Sensu em Ciência Jurídica da UNIVALI, Itajaí, v.10, n.4, $3^{\circ}$ quadrimestre de 2015. Disponível em: www.univali.br/direitoepolitica - ISSN 1980-7791.

como as recentes manifestações no Brasil parecem apontar para uma crise permanente desse sistema de governo.

Segundo dados do portal Latinobarómetro ${ }^{4}$, tomando por base as três maiores democracias da América Latina, ou seja, Brasil, Argentina e México, o percentual de pessoas que se dizem "muito satisfeitos" com a democracia é de apenas $6,2 \%$. "Satisfeitos" somam $26,8 \%$, enquanto que os que se dizem "não muito satisfeitos" ou "não satisfeitos de nenhuma maneira" somam 64\%. Segundo a mesma base de dados, apenas 52,7\% acreditam que a democracia é o melhor regime em qualquer circunstância, enquanto que quase $40 \%$ admitem que um governo autoritário pode ser melhor do que um democrático em algum momento. Além disso, mais da metade da população desses países considera que o governo de seus países é uma democracia "com graves problemas". Diante dos dados apresentados, o que pode ser constatado é que algo está preocupantemente errado.

Essa antiga discussão, de alguma maneira, ofuscou o debate acerca da apatia desses mesmos indivíduos em relação aos mecanismos de participação política já existentes. Muito se fala do fechamento do sistema de governo em relação à sociedade e, nesse sentido, aponta-se a participação política como solução ${ }^{5}$, mas tal análise não consegue prosperar sem responder ao questionamento em relação à negação por parte dos indivíduos de exercerem seus direitos políticos.

Dessa forma, empreender-se-á uma análise breve do problema - não deixando de considerar seus reflexos na questão da legitimidade - a partir de quatro principais marcos: Alexis de Tocqueville, Hannah Arendt, Jürgen Habermas e Immanuel Kant. À procura de caminhos que possam ser apontados como possíveis soluções, não se pretende, por óbvio, esgotar o que qualquer desses autores tenham estruturado sobre o assunto, senão tangenciar suas abordagens acerca da democracia e da representação que revolvam a presente abordagem.

\footnotetext{
${ }^{4}$ Dados disponíveis em http://www.latinobarometro.org/lat.jsp. Acesso em 20/09/2015.

${ }^{5}$ Habermas, ao propor um conceito de cidadania, coloca que tal só adquire forma e conteúdo no âmbito da participação nos processos democráticos de formação da opinião e vontade. Ver HABERMAS, Jürgen. Direito e democracia: entre facticidade e validade. Tradução de Flávio Beno Siebeneichler. Rio de Janeiro: Tempo Brasileiro, 1997, p. 108.
} 
LEMOS, Tayara Talita; DE ALMEIDA JUNIOR, Benedito Silva e DE MELLO, Larissa Fernandes Ranieri. O povo contra a democracia: o problema da abstenção dos indivíduos em relação ao exercício de seus direitos políticos. Revista Eletrônica Direito e Política, Programa de PósGraduação Stricto Sensu em Ciência Jurídica da UNIVALI, Itajaí, v.10, n.4, 30 quadrimestre de 2015. Disponível em: www.univali.br/direitoepolitica - ISSN 1980-7791.

\section{TOCQUEVILLE E OS LIMITES DA LIBERDADE NO ÂMBITO DA "NOVA" DEMOCRACIA - O PROBLEMA DA INSUFICIÊNCIA DO SISTEMA REPRESENTATIVO}

Logo quando do surgimento das primeiras democracias modernas, o francês Alexis de Tocqueville se debruçou sobre o tema, ao analisar o novo sistema de governo dos Estados Unidos, na obra Da Democracia na América ${ }^{6}$. Ao tomar como prisma de análise da democracia a liberdade - o direito pelo qual mais preza -, a preocupação do autor é explicar de que forma a associação de homens livres e iguais, como entende tal modo de governo, poderá propiciar autonomia e liberdades individuais de maneira a não gerar indiferença dos indivíduos uns em relação aos outros, o que, segundo ele, poderia fazer ruir esse novo modo de organização política - isso porque mesmo a partir do próprio exercício da liberdade é possível abrir caminho para o surgimento de um governo despótico ${ }^{7}$. Paradoxalmente, a democracia surgia contendo o potencial de dar origem à sua antítese, seja pela atuação de seus agentes políticos eleitos, seja pelo seu conteúdo individualista - e é essa segunda hipótese de destruição do ideal democrático que se pretende problematizar neste trabalho. Se a democracia nasce com um viés eminentemente liberal, os indivíduos balizam suas ações conforme o próprio arbítrio, orientando-se exclusivamente por seus interesses egoísticos. A partir do momento em que se abstém de exercer seus direitos políticos, fatalmente, o poder se concentrará nas mãos dos poucos que o fazem. A retração dos indivíduos para o âmbito de sua autonomia privada faz com que espaços vazios surjam no âmbito do sistema político e, dessa forma, é possível que, pelos próprios atos soberanos dos indivíduos, eles se submetam a um despotismo democrático ${ }^{8}$. Por isso mesmo, o princípio da soberania popular por si só não é uma garantia contra governos despóticos.

\footnotetext{
6 TOCQUeVILLE, Alexis de. Da democracia na América. Tradução de Eduardo Brandão. São Paulo: Martins Fontes, 2004 - reimpressão. Vide particularmente Cap.IV, parte II.

7 TOCQUEVILLE, Alexis de. Da democracia na América.

8 TOCQUEVILLE, Alexis de. Da democracia na América.
} 
LEMOS, Tayara Talita; DE ALMEIDA JUNIOR, Benedito Silva e DE MELLO, Larissa Fernandes Ranieri. O povo contra a democracia: o problema da abstenção dos indivíduos em relação ao exercício de seus direitos políticos. Revista Eletrônica Direito e Política, Programa de PósGraduação Stricto Sensu em Ciência Jurídica da UNIVALI, Itajaí, v.10, n.4, 30 quadrimestre de 2015. Disponível em: www.univali.br/direitoepolitica - ISSN 1980-7791.

Em análise dessa questão em Tocqueville, Marcelo Jasmin aponta para a menoridade política que se impõe, como reflexo de uma apatia política ou indiferença cívica:

O diagnóstico de Tocqueville acerca das sociedades modernas afirma que o individualismo inerente ao estado social democrático e o consequente confinamento dos homens nas esferas da privacidade são produtores de uma crescente indiferença cívica que constitui o caldo de cultura da emergência de um novo tipo de despotismo: uma forma de dominação política inédita ao mundo ocidental, que aparece como branda e tutelar, e que degrada os homens sem atormentá-los, mantendo os seus súditos, à maneira de um pátrio-poder sem fim, na eterna menoridade política. ${ }^{9}$

Esse tipo de poder que se ergue aniquilaria a liberdade sob o pretexto da liberdade. Sobre ele, Tocqueville explica: "Assim, todos os dias ele torna menos útil e mais raro o emprego do livre-arbítrio; encerra a ação da vontade num espaço menor e defrauda pouco a pouco cada cidadão até mesmo do uso de si. ${ }^{\prime 10}$

O despotismo democrático cria a ilusão de que os indivíduos estariam realizando intervenções reais nos destinos da coisa pública, na medida em que se valem da representação. Por meio de eleições, há a simulação da ideia de que há uma menor dependência e de que o autogoverno, em alguma medida, estaria garantido, uma vez que a democracia estaria assegurada, por meio dessa ínfima participação. Entretanto, a minoração dos prejuízos causados por essa ilusão criada por meio das eleições não extingue o mal da menoridade política. ${ }^{11}$

\footnotetext{
9 JASMIN, Marcelo. Despotismo e história na obra de Alexis de Tocqueville. In: Instituto de Estudos Avançados - USP. p.1 (disponível em: http://www.iea.usp.br/publicacoes/textos).

10 TOCQUeVILLE, Alexis de. A democracia na América. Tradução de Eduardo Brandão. São Paulo: Martins Fontes, 2004 - reimpressão. p.390.

${ }^{11}$ Conforme Jasmin: "O despotismo democrático apresenta-se para resolver a luta entre as paixões inimigas do homem moderno: o desejo de independência e a necessidade de ser conduzido. Em primeiro lugar, o novo poder não aparece como opressão pessoal. Sem rosto, é um poder de ninguém, senão do próprio povo de iguais." (JASMIN, Marcelo, Despotismo e história na obra de Alexis de Tocqueville. p.17).
} 
LEMOS, Tayara Talita; DE ALMEIDA JUNIOR, Benedito Silva e DE MELLO, Larissa Fernandes Ranieri. O povo contra a democracia: o problema da abstenção dos indivíduos em relação ao exercício de seus direitos políticos. Revista Eletrônica Direito e Política, Programa de PósGraduação Stricto Sensu em Ciência Jurídica da UNIVALI, Itajaí, v.10, n.4, 30 quadrimestre de 2015. Disponível em: www.univali.br/direitoepolitica - ISSN 1980-7791.

Daí que o conceito de liberdade adequado à essa realidade deveria ser concebido como autogoverno em dois sentidos, ou seja: como autonomia para reger sua conduta de acordo com seu próprio arbítrio e como influência no conteúdo das leis que irão balizar as suas ações. O autogoverno, nesse sentido, é o conteúdo político da liberdade. Tocqueville, mesmo sendo um liberal, entendia a suma importância da participação ativa de toda a sociedade nos processos políticos.

A preocupação de Tocqueville é legítima, a partir do momento em que a democracia nasce com um viés fortemente liberal, como já dito, que relega a participação popular nos processos políticos à mera escolha de representantes. Aliás, uma hipótese que aqui se levanta é que esse fenômeno de tendência à abstenção dos indivíduos no sentido de exercer seus direitos políticos deve-se muito à concepção moderna de democracia, que adota o sistema representativo, quase sempre exclusivo, em detrimento dos demais. ${ }^{12}$

Tal sistema é embasado na suposta impossibilidade de que os indivíduos deliberem dentro dos processos políticos, pelo número tão grandioso das populações e também pela conveniência de delegar a outrem o exercício dessas prerrogativas, obtendo assim maior espaço de autonomia privada, ao reduzir ao máximo o tempo e a dedicação necessários para a política. Dessa forma, os indivíduos escolhem, por meio do voto, os seus representantes, os quais tomarão as decisões políticas por eles. A interferência da sociedade nos processos políticos se daria, assim, quase que exclusivamente na eleição dos indivíduos que a conduziria. Não é necessário elaborar uma síntese complexa para entender que essa concepção restrita de processo de participação política teve consequências graves, principalmente no que diz respeito ao problema da legitimidade das decisões.

\footnotetext{
12 Ainda Marcelo Jasmin assim avalia o fenômeno do despotismo democrático: "A forma mais avançada do novo despotismo responde politicamente à ambigüidade da condição social democrática que ela mesma revela. Por um lado, ao se livrarem de todos os laços de dependência pessoal, os indivíduos desejam ser livres, julgar e agir segundo sua própria razão e obedecer apenas a si mesmos. Por outro, o isolamento e a privatização, transformando-os em ignorantes da coisa pública, impede-os de dirigir-se de modo autônomo, fazendo-os dependentes do poder estatal." (JASMIN, Marcelo, Despotismo e história na obra de Alexis de Tocqueville. p. 17).
} 
LEMOS, Tayara Talita; DE ALMEIDA JUNIOR, Benedito Silva e DE MELLO, Larissa Fernandes Ranieri. O povo contra a democracia: o problema da abstenção dos indivíduos em relação ao exercício de seus direitos políticos. Revista Eletrônica Direito e Política, Programa de PósGraduação Stricto Sensu em Ciência Jurídica da UNIVALI, Itajaí, v.10, n.4, 30 quadrimestre de 2015. Disponível em: www.univali.br/direitoepolitica - ISSN 1980-7791.

\section{HANNAH ARENDT: A IMPORTÂNCIA DO ESPAÇO PÚBLICO E DA PARTICIPAÇÃO POLÍTICA NA LEGITIMAÇÃO E NA CONSTRUÇÃO DAS AÇÕES}

Enquanto na esfera representativa o espírito público é deixado de lado e, em decorrência disso, cada vez menos os representantes são tratados pelos cidadãos como detentores legítimos de um poder que Ihes foi conferido ${ }^{13}$, na participação, o que se verifica é a falta de interesse nas decisões políticas, a desconfiança nos mecanismos participativos democráticos e desarticulação de movimentos sociais, associações e sindicatos.

Uma possibilidade de abordagem desse tema se faz a partir de algumas das principais concepções de Hannah Arendt. Antes disso, porém, é preciso perpassar alguns conceitos de grande relevância que Ihes são particulares e possuem significação própria. Isso porque, uma vez colocados lado a lado a outras ideias, procura-se ter o devido cuidado no uso e na distinção dos termos, de modo que a distância entre a filosofia política e as questões conceituais dos autores não seja desconsiderada.

Exemplo disso são os conceitos de espaço público e esfera pública tratados por Arendt e Habermas, respectivamente, como elementos que propiciam o acontecimento da política. Enquanto Habermas considera a esfera pública como um espaço de comunicação, informação e formação de opinião, em que as pessoas são dotadas de igualdade de condições discursivas e o público de indivíduos privados raciocinam juntos sobre assuntos públicos ${ }^{14}$, o espaço público de Arendt aponta para uma visão de mundo sob diferentes aspectos não redutíveis a uma única esfera, um espaço de aparência (em que os indivíduos aparecem uns aos outros) que permite a manifestação da pluralidade, sendo

13 EISENBERG, José. Comunidade ou república? Hannah Arendt e as linguagens do pensamento político contemporâneo. In: BIGNOTTO, Newton e JARDIM DE MORAES, Eduardo. Hannah Arendt: diálogos, reflexões e memórias. Belo Horizonte: Editora UFMG, 2001, p.173-174.

14 BENHABIB, Seyla. The Reluctant Modernism of Hannah Arendt. Oxford: Rowman \& Littlefield Publishers, 2003. 
LEMOS, Tayara Talita; DE ALMEIDA JUNIOR, Benedito Silva e DE MELLO, Larissa Fernandes Ranieri. O povo contra a democracia: o problema da abstenção dos indivíduos em relação ao exercício de seus direitos políticos. Revista Eletrônica Direito e Política, Programa de PósGraduação Stricto Sensu em Ciência Jurídica da UNIVALI, Itajaí, v.10, n.4, 30 quadrimestre de 2015. Disponível em: www.univali.br/direitoepolitica - ISSN 1980-7791.

impossível na contemporaneidade a reconstrução de um espaço público unificado ${ }^{15}$.

Assim, entende-se que o espaço público, no pensamento arendtiano, é o espaço político por excelência, onde as pessoas aparecem por completo, manifestam suas individualidades e reconhecem suas diferenças. E é justamente nessa convergência, chamada por Hannah Arendt de espaço-entre (in between) ${ }^{16}$, que se dá a construção da política.

Nesse sentido, é importante considerar uma concepção de liberdade para além da autonomia da vontade e da soberania - os primeiros sentidos convencionalmente usados -, isto é, para além de uma liberdade meramente individual. Quando a questão é participação política, a liberdade só se possibilita no espaço-entre-os-homens, no encontro de discursos, ações e diferenças e constitui, por isso mesmo, a razão de ser da política. Para Arendt, a política apenas tem sentido no espaço-entre (in-between), por meio da ação concertada (em concerto), plural e pública. Por paradoxal que possa parecer, é nesse instante, que as identidades pessoais, que são únicas, são construídas.

Para Arendt, em A Condição Humana,

A ação e o discurso são os modos pelos quais os seres humanos aparecem uns para os outros, certamente não como objetos físicos, mas enquanto homens. Esse aparecimento, em contraposição à mera existência corpórea, depende da iniciativa, mas trata-se de uma iniciativa da qual nenhum ser humano pode abster-se sem deixar de ser humano. Isso não ocorre com nenhuma outra atividade da vita activa. ${ }^{17}$

15 ORTEGA, Francisco. Para uma política da amizade: Arendt, Derrida e Foucault. Rio de janeiro: Sinergia- Relume-Dumará, 2009.

$16 \mathrm{O}$ espaço-entre (in-between), expressão usada por Hannah Arendt, diz respeito à possibilidade de conviver e relacionar-se com outras pessoas e, a partir da pluralidade, da comunicação e do diálogo, legitimar a política.

${ }^{17}$ ARENDT, Hannah. A Condição Humana. $11^{\text {a }}$ edição. Tradução de Roberto Raposo e Revisão Adriano Correia, Rio de Janeiro, Forense Universitária, 2010, da obra "A Condição Humana", p. 220-221. 
LEMOS, Tayara Talita; DE ALMEIDA JUNIOR, Benedito Silva e DE MELLO, Larissa Fernandes Ranieri. O povo contra a democracia: o problema da abstenção dos indivíduos em relação ao exercício de seus direitos políticos. Revista Eletrônica Direito e Política, Programa de PósGraduação Stricto Sensu em Ciência Jurídica da UNIVALI, Itajaí, v.10, n.4, 30 quadrimestre de 2015. Disponível em: www.univali.br/direitoepolitica - ISSN 1980-7791.

Assim, tem-se que a ação, atividade ligada à política, ${ }^{18}$ se estabelece a partir da alteridade e tem início no lançar-se ao espaço público, na iniciativa, no diálogo, na fala (ou palavra) e na pluralidade. Essa característica é o que propicia a liberdade, o "poder", enquanto capacidade de agir, e impede o isolamento, que destrói a pluralidade e conduz à perda do poder, acabando com as condições da vida política.

Com isso, busca-se compreender não só o esvaziamento do espaço público, mas esse fenômeno como uma espécie de esquecimento da política, manifesto em frequentes demonstrações de apatia cívica e política no mundo contemporâneo. O cidadão mostra-se cada vez mais indivíduo e menos cidadão, tendo em vista que os interesses privados são motivos de maior preocupação que os interesses públicos, ainda que existam mecanismos de ação e participação popular, não deixando de reconhecer que são insuficientes para a ampliação da democracia participativa.

De acordo com a autora, as democracias, em geral, têm sido marcadas pela ausência de espírito público e pela tendência a serem conduzidas por uma opinião massificada ${ }^{19}$. Para Hannah Arendt, ainda que, na democracia atual, abram-se possibilidades de diálogos, discussões, críticas e reconstruções de ideias, a invasão dos interesses privados no espaço público trazem sérios prejuízos à compreensão plural e colocam em risco a própria política ${ }^{20}$.

18 Para Hannah Arendt, a vida humana (chamada por ela de vita activa) é composta por três atividades, a ação, a obra (ou fabricação) e o trabalho. Enquanto a ação é a atividade que coloca o sujeito num espaço de construção política, público, a obra e o trabalho o colocam em constantes situações privadas. A atividade do trabalho como é a relacionada à vida biológica do ser humano e às satisfações de suas necessidades vitais, tendo como condição primordial a própria vida. O homem, aí compreendido como animal laborans, está sujeito às urgências, vicissitudes e necessidades e, por isso, é desprovido de liberdade. A atividade da obra (ou fabricação) reduz-se à capacidade que o homem (aqui entendido como homo faber) possui de produzir coisas e artefatos úteis à sua existência. Tem como condição o fato de o homem pertencer ao mundo e com ele se relacionar. A atividade da ação é aquela que apenas se desenvolve no espaço público, na presença de outros, no aparecimento de uns para os outros, compondo uma pluralidade capaz de transformar o mundo público. (ARENDT, Hannah. A Condição Humana. p. $8 \mathrm{ss}$ ).

19 ARENDT, Hannah. Da revolução. Tradução de Fernando Dídimo. 2.ed. Brasília: Editora Universidade de Brasília, 1990, p. 179-180.

20 LEMOS, T.T. Direito como fundação e Constituição como Promessa: um diálogo com Hannah Arendt._Dissertação de mestrado. Belo Horizonte: UFMG, p.101, 2012. 
LEMOS, Tayara Talita; DE ALMEIDA JUNIOR, Benedito Silva e DE MELLO, Larissa Fernandes Ranieri. O povo contra a democracia: o problema da abstenção dos indivíduos em relação ao exercício de seus direitos políticos. Revista Eletrônica Direito e Política, Programa de PósGraduação Stricto Sensu em Ciência Jurídica da UNIVALI, Itajaí, v.10, n.4, 30 quadrimestre de 2015. Disponível em: www.univali.br/direitoepolitica - ISSN 1980-7791.

\section{3. hABERMAS E A RELAÇÃO dAS AUTONOMIAS PÚBLICA E PRIVADA: O PROBLEMA DA LEGITIMIDADE DAS DECISÕES POLÍtICAS}

Habermas retoma o problema do esvaziamento do espaço público ${ }^{21}$ e os reflexos desse fenômeno na questão da legitimidade das decisões políticas. Segundo o autor, os dois paradigmas de Estado que mais obtiveram sucesso até os dias de hoje, o Estado Social e, principalmente, o Estado Liberal, não conseguiram apresentar respostas razoáveis para essas problemáticas.

Habermas remete à $\mathrm{Kant}^{22}$ nas suas considerações acerca da relação necessária entre as liberdades individuais (relacionadas à autonomia privada), entendidas tradicionalmente com um viés negativo, e o caráter positivo que devem adotar (relacionado à autonomia pública). Se é que a liberdade, num primeiro momento, é entendida como a faculdade que o indivíduo possui de conduzir a sua vida de acordo apenas com o seu próprio arbítrio, o único motivo razoável suscitado para limitá-la é a garantia da mesma faculdade a todos os outros indivíduos. Ora, consequência lógica desse conceito é que a limitação da liberdade deve se dar pelo próprio exercício dela, ou seja, o sistema do direito, na medida em que impõe normas de conduta a todos os indivíduos (e, dessa forma, colocando limites à autonomia deles), só é dotado de legitimidade a partir do momento em que os indivíduos reconhecem como tal as leis editadas por esse sistema. Daí que surge o caráter positivo das liberdades individuais.

Nesse sentido que Habermas concebe a equiprimordialidade entre as autonomias pública e privada ${ }^{23}$, o que segundo ele seria imprescindível para o bom funcionamento das democracias contemporâneas. Ao mesmo tempo que se confere ao indivíduo plena liberdade para construir seus ideais de vida boa e buscar sua realização, é importante que esses mesmos ideais sejam expressos em termos de participação política.

\footnotetext{
${ }^{21}$ HABERMAS, Jürgen. Direito e Democracia: entre facticidade e validade. p. 109.

22 HABERMAS, Jürgen. Direito e Democracia: entre facticidade e validade. p.48.

23 HABERMAS, Jürgen. Direito e Democracia: entre facticidade e validade. p. 48.
} 
LEMOS, Tayara Talita; DE ALMEIDA JUNIOR, Benedito Silva e DE MELLO, Larissa Fernandes Ranieri. O povo contra a democracia: o problema da abstenção dos indivíduos em relação ao exercício de seus direitos políticos. Revista Eletrônica Direito e Política, Programa de PósGraduação Stricto Sensu em Ciência Jurídica da UNIVALI, Itajaí, v.10, n.4, 30 quadrimestre de 2015. Disponível em: www.univali.br/direitoepolitica - ISSN 1980-7791.

O desafio que se coloca na contemporaneidade é o da busca da compatibilização das liberdades individuais e da autonomia privada com as exigências de um mínimo de bem-estar social e de participação política. A dicotomia público/privado deve ser superada e dar lugar a um modelo que comporte dentro de si os princípios de duas das mais conhecidas correntes de pensamento político, a saber, a dos liberais e a dos republicanos. Isso porque percebeu-se que "os processos de individuação e de socialização são interdependentes, de tal modo que não se podem reduzir os conflitos sociais a interindividuais ou a coletivos ${ }^{\prime 24}$. Nesse sentido, os processos políticos passaram a ser vistos como mais abrangentes que meros instrumentos de tomada de decisão e menos abrangentes do que a autorrealização ética da sociedade.

Lançando mão desses elementos é que o autor constrói a concepção da democracia procedimentalista, que se fundamenta na soberania do povo e da lei enquanto vontade geral da nação. Assim, ele dá uma resposta razoável aos clamores da sociedade moderna racionalizada e propicia o exercício da autonomia dos indivíduos (enquanto governar-se a si mesmo). Nesse sentido, as leis só são consideradas legítimas se possuírem aceitabilidade social, reconhecimento intersubjetivo dos indivíduos em relação a esse ordenamento jurídico enquanto válido ou, antes, a participação desses indivíduos na própria elaboração dos conteúdos normativos.

Não é necessário ir longe nesta análise para concluir que, a partir de quando se considera que o sistema do direito atual possui como pressuposto lógicofundamental a soberania do povo, tal sistema encontra-se gravemente comprometido se os indivíduos que o compõem se abstém de exercer suas faculdades políticas. Como já demonstrado aqui, o princípio da soberania popular por si só não constitui garantia suficiente contra governos autoritários. Tal princípio pode operar contra si mesmo - pois, se os indivíduos optam por alienar seu poder aos próprios agentes estatais que já o tem, a democracia é sufocada e pode facilmente dar lugar a um regime autoritário.

\footnotetext{
${ }^{24}$ HABERMAS, Jürgen. Direito e Democracia: entre facticidade e validade. p. 111.
} 
LEMOS, Tayara Talita; DE ALMEIDA JUNIOR, Benedito Silva e DE MELLO, Larissa Fernandes Ranieri. O povo contra a democracia: o problema da abstenção dos indivíduos em relação ao exercício de seus direitos políticos. Revista Eletrônica Direito e Política, Programa de PósGraduação Stricto Sensu em Ciência Jurídica da UNIVALI, Itajaí, v.10, n.4, 30 quadrimestre de 2015. Disponível em: www.univali.br/direitoepolitica - ISSN 1980-7791.

Habermas tenta compreender as razões pelas quais os indivíduos eventualmente adotam essa conduta de indiferença para com os processos políticos, e parece sintetizar seu argumento na seguinte citação:

A síndrome do privatismo da cidadania e o exercício do papel de cidadão na linha dos interesses de cliente tornam-se tanto mais plausíveis, quanto mais a economia e o Estado, que são institucionalizados através dos mesmos direitos, desenvolvem um sentido sistemático próprio, empurrando os cidadãos para o papel periférico de meros membros da organização. Os sistemas da economia e da administração tem a tendência de fechar-se contra seus mundos circundantes e de obedecer unicamente aos próprios imperativos do dinheiro e do poder administrativo. Eles rompem o modelo de uma comunidade de direito que se determina a si própria, passando pela prática dos cidadãos. ${ }^{25}$

Utilizando-se da teoria dos sistemas de Niklas Luhmann, o autor considera que, mesmo que o sistema de direito possua, dentro de si, mecanismos que permitem a participação política dos indivíduos, isso torna-se impossível na medida em que desenvolve uma lógica própria, distinta e destacada da dinâmica dos processos de socialização ${ }^{26}$.

No sentido da análise feita por Habermas na citação acima, as instituições políticas geridas pelo sistema representativo tornaram-se um sistema autopoiético $^{27}$, ou seja, funcionam de maneira a desenvolver uma linguagem própria e uma lógica orientada pela acumulação de poder administrativo, fechando-se em si mesmo e tornando-se imune às influências de outros sistemas

\footnotetext{
25 HABERMAS, Jürgen. Direito e Democracia: entre facticidade e validade. p. 109.

26 HABERMAS, Jürgen. HABERMAS, Jürgen. Direito e Democracia: entre facticidade e validade, p.74.

27 Segundo Luhmann a sociedade contemporânea pode ser concebida e analisada sob o prisma de sua teoria dos sistemas. Cada componente da realidade social pode ser entendido como um sistema, caso preencha a pré-condição de desenvolver uma técnica e uma linguagem próprias, necessárias para que os elementos componentes desse sistema possam se auto-reproduzir sendo dessa maneira auto-suficiente e fechando-se para seu mundo circundante, ou seja, todos os outros sistemas que compõem o tecido social. Nesse sentido o Direito corresponde a essa précondição na medida em que desenvolveu uma técnica própria para se auto-reproduzir, a saber, o estabelecimento de procedimentos no âmbito das corporações legislativas. Para mais, ver LUHMANN, Niklas. Legitimação pelo procedimento. Tradução de Maria da Conceição Côrte Real. Brasília, Editora da Universidade de Brasília, 1980.
} 
LEMOS, Tayara Talita; DE ALMEIDA JUNIOR, Benedito Silva e DE MELLO, Larissa Fernandes Ranieri. O povo contra a democracia: o problema da abstenção dos indivíduos em relação ao exercício de seus direitos políticos. Revista Eletrônica Direito e Política, Programa de PósGraduação Stricto Sensu em Ciência Jurídica da UNIVALI, Itajaí, v.10, n.4, 30 quadrimestre de 2015. Disponível em: www.univali.br/direitoepolitica - ISSN 1980-7791.

- notadamente do mundo da vida ${ }^{28}$, com o qual deveria guardar estreita relação. Disso resulta um sistema político isolado do contexto no qual se insere. Um sistema democrático que se mostra totalmente alheio à facticidade do tecido social se torna deficiente, de maneira a relegar aos cidadãos o papel de meros membros da organização política. Se os processos decisórios se diferenciam substancialmente dos próprios processos de socialização concebidos no mundo da vida, o próprio sistema político fica seriamente comprometido em relação aos fins aos quais se propõe. Segundo Habermas ${ }^{29}$ :

Os sistemas da economia e da administração tem a tendência de fechar-se contra seus mundos circundantes e de obedecer unicamente aos próprios imperativos do dinheiro e do poder administrativo. Eles rompem o modelo de uma comunidade de direito que se determina a si própria, passando pela prática dos cidadãos.

Tem-se, dessa maneira, o comprometimento sério do mecanismo que nutria as instituições políticas de legitimidade - situação essa que, aliás, só se reforça se se tem em mente os dados estatísticos apresentados na introdução.

Tal lógica, por si só, mantém-se distante do domínio dos indivíduos por desenvolver também um conhecimento técnico próprio, o que dificulta em muito a acessibilidade a esse conhecimento e, consequentemente, ao próprio processo decisório. Nesse sentido é que a abstenção destes em relação aos mesmos processos parece seguir uma via de mão dupla: ao mesmo tempo em que os indivíduos se negam a deliberar ou a participar da elaboração dos conteúdos normativos, deixam que tal prerrogativa seja exercida por aqueles que já se encontram inseridos no sistema político e esse, pelo mesmo motivo, desenvolve um sentido próprio que é compartilhado apenas pelos mesmos agentes governamentais. É assim que o sistema político fecha-se em relação ao seu mundo circundante, fazendo com que o exercício do poder político seja um fim em si mesmo, impossibilitando inclusive que qualquer conteúdo normativo

\footnotetext{
${ }^{28}$ Mundo da vida é o conceito habermasiano que exprime o plexo de orientações valorativas, normas morais e signos linguísticos compartilhados por todos os indivíduos da comunidade, pelo simples fato de estarem inseridos nela e no seu âmbito terem sido socializados. HABERMAS, Jürgen. Direito e Democracia: entre facticidade e validade, p. 40.

${ }^{29}$ HABERMAS, Jürgen. Direito e Democracia: entre facticidade e validade. p. 109.
} 
LEMOS, Tayara Talita; DE ALMEIDA JUNIOR, Benedito Silva e DE MELLO, Larissa Fernandes Ranieri. O povo contra a democracia: o problema da abstenção dos indivíduos em relação ao exercício de seus direitos políticos. Revista Eletrônica Direito e Política, Programa de PósGraduação Stricto Sensu em Ciência Jurídica da UNIVALI, Itajaí, v.10, n.4, $3^{\circ}$ quadrimestre de 2015. Disponível em: www.univali.br/direitoepolitica - ISSN 1980-7791.

produzido por esse sistema político seja revestido de qualquer indício de legitimidade, se se propõe, com Habermas, que "são válidas as normas de ação às quais todos os possíveis atingidos poderiam dar o seu assentimento, na qualidade de participantes de discursos racionais" ${ }^{\prime 30}$.

Nesse sentido, dois processos aparentemente se retro-alimentam: de um lado, o fechamento do sistema jurídico-político, sob a lógica do poder pelo poder e da predominância dos interesses individuais, empurram os cidadãos para o papel de meros membros da organização; o exercício do poder político sob essas bases certamente corrói qualquer pretensão à efetivação do bem comum, prejudicando o seu sentido e comprometendo as bases republicanas do sistema democrático. Ora, a estrutura do citado sistema pressupõe que os cidadãos abram mão de seus interesses individuais, em certas ocasiões, em prol mesmo do bem comum, na boa-fé de que seus semelhantes farão o mesmo. Por óbvio, se há a subversão dessa lógica de orientação do agir político e estratégico em prol de interesses individuais (em termos tocquevilianos, a predominância do interesse mal compreendido) ocorre a implosão de todos os fundamentos lógicos sob os quais a democracia, ou antes, a república democrática, se apóia.

Nesse mesmo sentido, cabe aqui uma digressão acerca da maneira de agir dos cidadãos em relação uns aos outros no âmbito de uma sociedade democrática. Para Habermas ${ }^{31}$, a postura condizente com os princípios e objetivos fundamentais de uma democracia republicana é aquela conduzida pelo agir comunicativo, conceito filosófico que pode ser definido como o orientado pelo entendimento, pelo qual o indivíduo assume a posição de participante no procedimento de formação democrática da opinião, reconhecendo seus interlocutores como dotados dos mesmos direitos que ele próprio a fim de atingir um conteúdo normativo que possa ser reconhecido como válido por todos, para que todos adequem o seu comportamento e orientem as suas ações de acordo com esse conteúdo. Se opõe ao agir estratégico, pelo qual o indivíduo adota uma

\footnotetext{
${ }^{30}$ HABERMAS, Jürgen. Direito e Democracia: entre facticidade e validade. p. 142.

${ }^{31}$ HABERMAS, Jürgen. Direito e Democracia: entre facticidade e validade., p. 40.
} 
LEMOS, Tayara Talita; DE ALMEIDA JUNIOR, Benedito Silva e DE MELLO, Larissa Fernandes Ranieri. O povo contra a democracia: o problema da abstenção dos indivíduos em relação ao exercício de seus direitos políticos. Revista Eletrônica Direito e Política, Programa de PósGraduação Stricto Sensu em Ciência Jurídica da UNIVALI, Itajaí, v.10, n.4, $3^{\circ}$ quadrimestre de 2015. Disponível em: www.univali.br/direitoepolitica - ISSN 1980-7791.

perspectiva egoísta e orienta as suas ações a partir de elementos finalísticos, visando o seu sucesso.

O agir orientado pelo entendimento, nesse sentido, tem como pressuposto o estabelecimento de canais de comunicação entre as instituições políticas e os cidadãos, de maneira a possibilitar que esses influenciem nas discussões no âmbito daquelas, sendo a todo o tempo confrontadas com a opinião pública. 0 ponto de partida para uma tentativa de resolução do problema, nesse sentido, parece ser a gradativa abertura do sistema político, uma vez autopoiético, a fim de ser permeado e influenciado pelos conteúdos originados da sociedade, em obediência ao princípio da soberania popular - pois os agentes da administração pública tendem a levar mais em consideração o imperativo do bem comum quando confrontados com a opinião pública, e nesse sentido as decisões no âmbito das esferas do poder público podem se dar no âmbito de um prolongado processo de reflexão coletiva.

\section{KANT E A "MENORIDADE POLÍtICA"}

Na medida em que a visão kantiana influencia Habermas, principalmente no que diz respeito à questão do exercício das liberdades individuais exclusivamente no âmbito da autonomia privada, faz-se relevante uma abordagem do tema aqui trabalhado a partir das concepções de Kant. Se se considera a adoção do sistema representativo de governo e o posterior fechamento do sistema político em si mesmo, bem como as noções de "menoridade" e "esclarecimento" kantianas, é possível que se empreenda um contraste de ideias. Surge, ainda, a possibilidade de uma nova hipótese, pela qual se questiona o início da inércia política dos indivíduos. 
LEMOS, Tayara Talita; DE ALMEIDA JUNIOR, Benedito Silva e DE MELLO, Larissa Fernandes Ranieri. O povo contra a democracia: o problema da abstenção dos indivíduos em relação ao exercício de seus direitos políticos. Revista Eletrônica Direito e Política, Programa de PósGraduação Stricto Sensu em Ciência Jurídica da UNIVALI, Itajaí, v.10, n.4, 30 quadrimestre de 2015. Disponível em: www.univali.br/direitoepolitica - ISSN 1980-7791.

Kant, ao descrever a dinâmica pré-moderna do exercício do poder terreno pela Igreja em seu texto Resposta à pergunta o que é o Iluminismo ${ }^{32}$, acaba por oferecer ferramentas teóricas adequadas para se empreender a tentativa de analisar o problema da abstenção do exercício dos direitos políticos.

Inserido no seu contexto histórico está a derrocada do poder da Santa Sé no que diz respeito à tutela desta em relação aos indivíduos, ao que ditava autoritariamente o que deviam fazer, qual padrão de atitude adotar e até o que deveriam pensar, sentir e no que crer, de maneira que Kant denomina a situação desses indivíduos de "menoridade":

A minoridade é a incapacidade de se servir de seu próprio entendimento sem a tutela de um outro. É a si próprio que se deve atribuir essa minoridade, uma vez que ela não resulta da falta de entendimento, mas da falta de resolução e de coragem necessárias para utilizar seu entendimento sem a tutela de outro. [...] A preguiça e a covardia são as causas pelas quais uma parte tão grande dos homens, libertos há muito pela natureza de toda tutela alheia (naturaliter majorennes), comprazem-se em permanecer por toda sua vida menores; e é por isso que é tão fácil a outros instituírem-se seus tutores. É tão cômodo ser menor. Se possuo um livro que possui entendimento por mim, um diretor espiritual que possui consciência em meu lugar, um médico que decida acerca de meu regime, etc., não preciso eu mesmo esforçar-me. Não sou obrigado a refletir, se é suficiente pagar; outros se encarregarão por mim da aborrecida tarefa ${ }^{33}$.

O ponto que aproxima definitivamente esta análise da que se pretende aqui é o fato de que, da mesma forma que a Igreja adquiriu a supremacia do

32 KANT, Immanuel. Resposta à pergunta o que é o Iluminismo. Disponível em: < http://www.lusosofia.net/textos/kant_o_iluminismo_1784.pdf>. Acesso em: 22 nov 2015.

${ }^{33}$ KANT, Immanuel. Resposta à pergunta o que é o Iluminismo. p. 1 e 2. 
LEMOS, Tayara Talita; DE ALMEIDA JUNIOR, Benedito Silva e DE MELLO, Larissa Fernandes Ranieri. O povo contra a democracia: o problema da abstenção dos indivíduos em relação ao exercício de seus direitos políticos. Revista Eletrônica Direito e Política, Programa de PósGraduação Stricto Sensu em Ciência Jurídica da UNIVALI, Itajaí, v.10, n.4, 30 quadrimestre de 2015. Disponível em: www.univali.br/direitoepolitica - ISSN 1980-7791.

conhecimento durante a Idade Média, ditando a toda a sociedade o que deveriam fazer ou o que deveriam pensar, as classes que tradicionalmente detém o poder político exercem papel semelhante nas democracias contemporâneas na medida em que grande parte dos indivíduos aliena seu direito de influir nos processos políticos a essas classes.

Aparentemente, os indivíduos afinal se libertaram de sua menoridade moral, pensando por si mesmos e por si mesmos concebendo seus valores, crenças e ideais de vida boa. Pode-se questionar, no entanto, se ainda estariam sob o jugo de uma espécie de "menoridade política". Isso porque, no atual sistema representativo de governo, os indivíduos possuem uma tendência a adotar uma postura inerte frente às decisões que se concebem nos processos políticos e são, de certa forma, tutelados politicamente por aqueles já inseridos nesses processos. Assim, os cidadãos abrem mão de pensar com autonomia e de agir por conta própria no que diz respeito ao exercício de seus direitos políticos.

Compreensões no sentido de que o voto em nada altera o cenário político vigente ou de que a falta de participação política se dá em razão do desconhecimento dos processos decisórios e dos mecanismos participativos são recorrentes. Frases do tipo "todos os políticos são iguais" ou "política não se discute" fazem parte de um discurso do senso comum que é o próprio reflexo da síndrome da "menoridade política". Essa mesma "menoridade" parece ser demonstrada às claras todas as vezes em que esse discurso de descrença política é reiterado e, assim, corroborado.

A saída da menoridade, isto é, o esclarecimento ${ }^{34}$, só é possível pelo pensamento autônomo. Com isso, enxerga-se certa indisposição à tentativa de influenciar nos processos políticos ou à assunção da responsabilidade de discutir ideias no âmbito de sua autonomia pública. Há, assim, alienação dessa prerrogativa a outros indivíduos, quase sempre agentes governamentais já inseridos no sistema

\footnotetext{
34 "Esclarecimento (Aufklärung) significa a saída do homem de sua minoridade, pela qual ele próprio é responsável." KANT, Immanuel. Resposta à pergunta o que é o Iluminismo.
} 
LEMOS, Tayara Talita; DE ALMEIDA JUNIOR, Benedito Silva e DE MELLO, Larissa Fernandes Ranieri. O povo contra a democracia: o problema da abstenção dos indivíduos em relação ao exercício de seus direitos políticos. Revista Eletrônica Direito e Política, Programa de PósGraduação Stricto Sensu em Ciência Jurídica da UNIVALI, Itajaí, v.10, n.4, 30 quadrimestre de 2015. Disponível em: www.univali.br/direitoepolitica - ISSN 1980-7791.

político, para que sejam seus tutores ${ }^{35}$ e possam decidir livremente em nome deles. Tal é a consequência da exacerbação do exercício das liberdades individuais e de se levar o sistema representativo de governo às últimas consequências.

\section{CONSIDERAÇÕES FINAIS}

A partir da busca de hipóteses para a apatia política, ainda que em uma república democrática, é fácil perceber que o sistema político obedece a uma dinâmica que claramente vai contra os próprios fins aos quais se propõe. Com a análise dos autores escolhidos, ainda que de maneira breve, entendendo suas peculiaridades conceituais e contextuais, a intenção é demonstrar que as causas levantadas para essa questão não podem se ater a uma visão política específica, sem que haja uma devida abertura para discussões.

Em última instância, o problema da renúncia dos indivíduos do exercício de seus direitos políticos parece se ligar à própria estrutura do sistema político atual, o qual se fecha em si mesmo e desenvolve uma lógica própria, alheia ao processo de socialização e de reconhecimento intersubjetivo da ordem jurídica. Por sua vez, o fenômeno do fechamento do sistema político se origina de uma concepção muito restrita do sistema representativo de governo, que estimula os indivíduos a simplesmente alienarem seus poderes políticos a um pequeno grupo de pessoas, quase sempre já pertencente à elite política, para que decidam por todos eles.

Tal fenômeno provoca, por consequência, a crise de legitimidade pela qual o sistema político atual passa. Novamente, se o princípio da soberania popular é a pedra angular na qual todo o exercício do poder político se apóia (no sentido do

\footnotetext{
35 Termo utilizado por Kant para referir-se àqueles que orientam, instruem e direcionam as ações dos "menores". Estes, por sua vez, são incapazes de servirem de seu próprio entendimento sem a tutela de um outro e, por isso, transferem para um terceiro a responsabilidade da reflexão.
} 
LEMOS, Tayara Talita; DE ALMEIDA JUNIOR, Benedito Silva e DE MELLO, Larissa Fernandes Ranieri. O povo contra a democracia: o problema da abstenção dos indivíduos em relação ao exercício de seus direitos políticos. Revista Eletrônica Direito e Política, Programa de PósGraduação Stricto Sensu em Ciência Jurídica da UNIVALI, Itajaí, v.10, n.4, 30 quadrimestre de 2015. Disponível em: www.univali.br/direitoepolitica - ISSN 1980-7791.

conceito de autogoverno), é necessário que o sistema político se mostre cada vez mais "poroso" às interferências da sociedade, sensível às opiniões e valores que se reconhecem no seu âmbito, se quiser se fazer claramente democrático.

\section{REFERÊNCIAS DAS FONTES CITADAS}

ARENDT, Hannah. A Condição Humana. Tradução de Roberto Raposo e Revisão Adriano Correia. Rio de Janeiro: Forense Univesitária,2001

Entre o passado e o futuro. São Paulo: Perspectiva. 2000.

Da revolução. Tradução de Fernando Dídimo. 2.ed. Brasília: Editora Universidade de Brasília, 1990,

BENHABIB, Seyla. The Reluctant Modernism of Hannah Arendt. Oxford: Rowman \& Littlefield Publishers, 2003.

EISENBERG, José. Comunidade ou república? Hannah Arendt e as linguagens do pensamento político contemporâneo. In: BIGNOTTO, Newton e JARDIM DE MORAES, Eduardo. Hannah Arendt: diálogos, reflexões e memórias. Belo Horizonte: Editora UFMG, 200.

JASMIN, Marcelo. Despotismo e história na obra de Alexis de Tocqueville. In: Instituto de Estudos Avançados - USP. p.1 (disponível em: http://www.iea.usp.br/publicacoes/textos).

LEMOS, Tayara Talita. Direito como fundação e Constituição como Promessa: um diálogo com Hannah Arendt. Dissertação de mestrado. Belo Horizonte: UFMG. 2012.

LUHMANN, Niklas. Legitimação pelo procedimento. Tradução de Maria da Conceição Côrte Real. Brasília, Editora da Universidade de Brasília, 1980

SINTOMER, Yves. O poder ao povo: júris de cidadãos, sorteio e democracia participativa. Belo Horizonte: Editora UFMG, 2010 
LEMOS, Tayara Talita; DE ALMEIDA JUNIOR, Benedito Silva e DE MELLO, Larissa Fernandes Ranieri. O povo contra a democracia: o problema da abstenção dos indivíduos em relação ao exercício de seus direitos políticos. Revista Eletrônica Direito e Política, Programa de PósGraduação Stricto Sensu em Ciência Jurídica da UNIVALI, Itajaí, v.10, n.4, $3^{\circ}$ quadrimestre de 2015. Disponível em: www.univali.br/direitoepolitica - ISSN 1980-7791.

HABERMAS, Jürgen. Direito e democracia: entre facticidade e validade. Tradução de Flávio Beno Siebeneichler. Rio de Janeiro: Tempo Brasileiro, 1997.

ORTEGA, Francisco. Para uma política da amizade: Arendt, Derrida e Foucault. Rio de janeiro: Sinergia- Relume-Dumará, 2009.

TOCQUEVILLE, Alexis de. Da democracia na América. Tradução de Eduardo Brandão. São Paulo: Martins Fontes, 2004 - reimpressão.

KANT, Immanuel. Reposta à pergunta: O que é Iluminismo? Tradução de Luiz Paulo Rouanet. Disponível em: <http://ensinarfilosofia.com.br/_pdfs/e_livors/47.pdf>. Acesso em: 05 dez 2014.

http://www.latinobarometro.org/lat.jsp. Acesso em 20/09/2015.

Submetido em: Setembro/2015

Aprovado em: Dezembro/2015 